\title{
O MÉTODO PROBLEMATIZADOR NO CUIDADO EDUCATIVO COM MULHERES NO PREPARO AO PARTO*
}

\author{
Andréia Maria Damascenoํㅜ Fátima Aparecida Said ${ }^{2}$
}

\begin{abstract}
RESUMO: Trata-se de estudo de abordagem qualitativa, realizado em 2007, para avaliar prática educativa com a aplicação do Método Problematizador, em preparo para o parto de grupo de sete mulheres. Foram realizadas sete oficinas pedagógicas em unidade de saúde municipal da cidade de Curitiba - PR. As oficinas tiveram duração aproximada de duas horas com aplicação das etapas do Método Problematizador. As práticas educativas oportunizaram suporte social, informativo e de apoio para diminuir o estresse e o medo quanto ao parto. Concluiu-se que o método é ativo, porque oportuniza a expressão do pensamento e das experiências pessoais do grupo, também é reflexivo, porque para falar de uma realidade ou resolver problema, defender uma idéia, o grupo precisa analisar, julgar, propor soluções e usar suas capacidades mentais, situações essas que ocorrem na prática educativa.
\end{abstract}

PALAVRAS-CHAVE: Educação em Saúde; Método Problematizador; Parto.

\section{PROBLEM-BASED METHODOLOGY IN WOMEN'S EDUCATIONAL CARE AS A PREPARATION FOR DELIVERY}

\begin{abstract}
It is a qualitative study, carried out in 2007, aiming to evaluate educational practice with the application of problem-based methodology in the preparation for delivery of a group of 07 women. Seven (07) pedagogical workshops were held at a Municipal Health Center in the city of Curitiba - Parana State, Brazil. The workshops lasted about two hours with the application of the steps of the problem-based method. These educational practices brought about social support, information and support to relieve stress and labor fear. It was concluded that the method is active, because it allows thought expression as well as the expression of the group's personal experiences, but it is also thought-provoking because the group needs to analyze, to judge, to bring up solutions and to use their mental capacities in order to talk about reality or solve problems and defend an idea; such situations occur in educational practice.
\end{abstract}

KEYWORDS: Health Education; Problem-based methodology; Delivery.

\section{METODOLOGÍA PROBLEMATIZADORA EN EL CUIDADO EDUCATIVO CON MUJERES EN LA PREPARACIÓN DEL PARTO}

RESUMEN: Este artículo constituye una parte de estudio que tiene por objetivo evaluar una práctica educativa con el uso de la metodología problematizadora en la preparación de un grupo de siete mujeres embarazadas. Fueron siete cursos de capacitación pedagógica en un centro médico municipal de la ciudad de Curitiba entre 01/08 y 08/09 de 2007. Los cursos tenían duración de dos horas aproximandamente y eran organizados en tres momentos, con aplicación de las etapas de la metodología. Las prácticas educativas posibilitaron soporte social, informativo y ayudaron a disminuir el miedo del parto. Se concluyó que el método es activo, porque permite la expresión del pensamiento y las experiencias personales del grupo; y también reflexivo, pues, para hablar de una realidad o para decidir un problema o defender a una Idea, el grupo necesita analizar, juzgar, considerar soluciones y utilizar sus capacidades mentales, lo que constituyen situaciones de práctica educativa.

PALABRAS-CLAVE: Metodología problematizadora; Educación en Salud; Parto.

*Excerto de monografia de Graduação em Enfermagem. 2007. Faculdade Evangélica do Paraná-FEPAR.

${ }^{1}$ Enfermeira graduada pela FEPAR.

${ }^{2}$ Professora Adjunta do Curso de Graduação em Enfermagem da FEPAR. Mestre em Assistência de Enfermagem pela Universidade Federal de Santa Catarina-UFSC. Orientadora.

Autor correspondente:

Fátima Aparecida Said

Rua Paula Gomes, 779 - 80510-070 - Curitiba-PR Recebido: 27/03/08

E-mail: fatimasaid702@yahoo.com.br 


\section{INTRODUÇÃO}

A educação é o ato de refletir a evidência de um cuidado, propondo a humanização das relações e a libertação dos seres humanos para se superarem em situações de vida e saúde. A educação, então, é um processo vivencial de articulação de saberes que pode se dar com comunidades e ambientes de saúde ${ }^{(1)}$.

Uma verdadeira libertação somente é possível se houver uma atuação transformadora da situação opressora. O diálogo é uma exigência existencial, é o encontro dos homens, mediatizados pelo mundo para pronunciá-lo;

é pelo diálogo que o homem descobre a realidade e seus desafios, estabelecendo, assim, a relação reflexiva do homem com outros homens e com o mundo ${ }^{(2: 30)}$.

Para realizar o cuidado educativo na intencionalidade de promover transformações nas pessoas e sua realidade o enfermeiro dispõe de diversas metodologias educativas, entre elas, a do Método Problematizador que constitui uma alternativa dinâmica, ativa, reflexiva e transformadora.

O Método Problematizador é uma possibilidade metodológica que tem imenso potencial didáticopedagógico para preparar o ser humano, ajudando-o a enfrentar os desafios do autoconhecimento e das suas relações com uma sociedade que passa por várias transformações ${ }^{(3)}$. É um método de ensino dinâmico, ativo, mobilizador de reflexão-ação-reflexão e de caráter transformador ${ }^{(4)}$. Por seus fundamentos teórico-metodológicos, põe-se sua indicação para as práticas educativas dos enfermeiros.

Neste estudo a questão norteadora esteve posta pela seguinte indagação: O Método Problematizador se constitui uma alternativa metodológica ativa, reflexiva, transformadora para preparar educativamente as gestantes para o parto?

O objetivo geral foi avaliar a aplicação do Método Problematizador no cuidado educativo de um grupo de mulheres gestantes e como objetivos específicos verificar o pressuposto do Método Problematizador como método ativo, reflexivo e transformador; levantar por meio de um processo educativo problematizador, as necessidades de cuidados e conhecimentos de um grupo de mulheres gestantes no preparo ao parto; preparar educativamente o grupo de mulheres gestantes ao parto, pelo princípio pedagógico da ação-reflexão-ação.

O CAMINHO METODOLÓGICO CONSTRUÍDO
Esta pesquisa constituiu-se de estudo de natureza qualitativa e descritiva em que se utilizou processo grupal, para a investigação da aplicação do Método Problematizador, no cuidado educativo de um grupo de mulheres gestantes, no preparo para o parto.

O Método Problematizador faz parte das metodologias ativas de ensino que se preocupam com o aumento da capacidade do educando participante e agente de transformação. Ele serve para detectar os problemas reais e buscar para eles soluções originais e criativas ${ }^{(5)}$. Este método entende a educação como atividade mediadora entre o indivíduo e a sociedade; ele parte de uma realidade de interesse do grupo e a ela retorna após um processo organizado de síncrese, análise e síntese do conhecimento pelo grupo.

Com a técnica da observação foi possível coletar em cada etapa do método os dados de interesse à análise do estudo. Esses dados também foram coletados através da gravação em transcrição posterior dos diálogos ocorridos no grupo, na realização de oficinas pedagógicas. Por oficinas, ficou entendido a seqüência de encontros em que a temática geral é estruturada, usando-se diferentes técnicas e estratégias didáticas que possam ser facilitadoras e problematizadoras das questões, auxiliando os participantes a exporem seus conhecimentos e, assim, favorecer o processo de troca e de crescimento geral do grupo ${ }^{(6)}$.

O cenário das oficinas pedagógicas foi a sala de reuniões de um Centro Médico da Secretaria Municipal de Saúde de Curitiba, realizadas às sextasfeiras no período de 01/08 a 28/09/2007. Estas oficinas tiveram a participação de sete gestantes, com duração aproximada de duas horas, e foram organizadas pedagogicamente da seguinte maneira: primeiro se realizava o momento de acolhimento do grupo, seguido do momento de aplicação da etapa do Método Problematizador ou Método do Arco e encerrado com um momento da confraternização grupal.

Tomaram-se como critérios pré-estabelecidos à amostra, ser gestante com idade maior de 18 anos e estar cadastrada no Programa Saúde da Mulher, com até 30 semanas de gestação. $\mathrm{O}$ projeto foi aprovado pelo Comitê de Ética e Pesquisa, sob n ${ }^{\circ}$ 2471/07 da Sociedade Evangélica Beneficente de Curitiba.

\section{Descrição das práticas educativas}

As práticas educativas foram realizadas por meio de oficinas, nomeadas pelas pesquisadoras. 


\section{$1^{a}$ Oficina: conhecendo-nos como grupo}

Esta oficina teve como objetivos explicar o projeto às mulheres gestantes presentes, formalizar legalmente a participação das mesmas.

Foram esclarecidos os objetivos da pesquisa, bem como garantia do caráter confidencial e do anonimato de informações. As participantes foram nomeadas pela letra $(G)$ e por seqüência numérica, como por exemplo, (G.1) até a última participante (G.7). Em seguida, foram iniciadas duas dinâmicas, uma de apresentação de cada gestante e outra de integração grupal. Nestas dinâmicas percebemos que as gestantes participaram ativamente e ao final, elas demonstravam que se sentiam acolhidas, descontraídas e interessadas. Estavam mais espontâneas nas falas e ao irem embora se mostravam mais comunicativas.

Foi notório que a empatia, a receptividade e disponibilidade do facilitador, aqui nomeado como um dos pesquisadores ajudou a conduzir o grupo à atividade e à satisfação. Em seguida, foi feito um convite ao cofee-break, e agendado o próximo encontro, respeitando-se escolha de horário e dias solicitados pelo próprio grupo.

\section{$2^{a}$ Oficina: iniciando o Método Problematizador na Observação da Realidade do Parto e seus Pontos-Chave}

Esta oficina caracterizou-se pelo início da aplicação do Método Problematizador em suas etapas de Observação da Realidade e Levantamento de Pontos-Chave.

A primeira etapa do método denomina-se Observação da Realidade social. Nessa fase o grupo é orientado pelo coordenador a levantar aspectos de uma realidade social, que de alguma forma constituam problemas a serem resolvidos durante a aplicação do método. Essa observação permite ao grupo expressar suas percepções pessoais, identificando dificuldades, carências, discrepâncias, de várias ordens, problemas, contradições que serão problematizados pelo coordenador do grupo com o mesmo ${ }^{(5)}$.

Em uma segunda etapa ou fase nomeada de Levantamento de Pontos-Chave, o grupo é levado a refletir primeiramente sobre as possíveis causas da existência do problema ou assunto, suas variáveis e determinantes: Por que será que existe esse problema? Nessa fase, o grupo percebe que existem variáveis menos diretas, menos evidentes, mais distantes, mas que interferem na existência daquele problema em estudo; são esses os Pontos-Chave que serão desenvolvidos na próxima etapa. As observações feitas nessa fase servirão para dar embasamento à próxima fase: a da Teorização(5).

Nesta segunda oficina iniciou-se com a realização de uma dinâmica de integração grupal intitulada “Onde está o meu par?” A participação do grupo foi interativa e muito divertida, favorecendo a descontração das mulheres gestantes. A seguir foram expostos os objetivos do encontro e explicado a sua condução didática que esta constaria de dois momentos: o primeiro o facilitador faria perguntas ao grupo para respondê-las e o segundo momento, o grupo levantaria pontos importantes sobre as respostas dadas às perguntas do facilitador.

As perguntas dirigidas ao grupo foram: O que é o parto? O parto pode ser uma experiência com problemas? Por quê? Quais os problemas relativos ao parto? Por que esses problemas aparecem? O que vocês gostariam que tratássemos sobre o parto nos próximos encontros?

As respostas com as percepções sobre o parto, problemas, cuidados, expectativas, crenças e medos do grupo foram registradas no flip-chart pelo facilitador. Os problemas levantados foram descritos em termo do que era o problema, como ele se dava, onde se dava, e porquê se dava, uma vez que a intenção pedagógica era conduzir o grupo à reflexão. As respostas e relatos do grupo, anotados no flip-chart, reproduziram de maneira fiel o discurso das mulheres gestantes presentes.

Em um segundo momento do Método Problematizador, o do levantamento de Pontos-Chave, o facilitador provocou a reflexão do grupo sobre causas e fatores determinantes da situação descrita em suas falas. A intenção foi priorizar que conteúdos o grupo gostaria de discutir nas próximas oficinas. Os PontosChave levantados foram: tipos de parto, sinais do parto e tempo do trabalho de parto, humanização no parto, dor e medo do parto e direitos das gestantes.

Utilizando um instrumento de avaliação da oficina verificou-se que cinco mulheres gestantes saíram satisfeitas e desejando que houvesse mais encontros como este; uma delas externou que ainda possuía dúvidas do encontro. Foi explicado a ela que paulatinamente, nas oficinas seguintes, as dúvidas seriam esclarecidas.

$3^{a}$ Oficina: aprendendo mais sobre sinais do parto 
Nesta oficina com o Método Problematizador, em sua etapa de Teorização, compareceram ao encontro cinco mulheres gestantes. Nesse encontro iniciamos a Teorização de um dos Pontos-Chave, sinais do parto, levantados pelo grupo no encontro anterior.

Para esta primeira oficina de teorização foi preparada uma série de figuras em forma de pequenos cartazes ilustrando os sinais de parto, as quais foram espalhadas pelo chão da sala para observação do grupo, disposto de forma circular. Ao convite do facilitador, cada mulher gestante deveria escolher uma figura, explicá-la, colocando-a na seqüência dos conhecimentos relativos aos sinais de parto. Coube ao facilitador mediar a discussão entre as mulheres gestantes, esclarecer e complementar conhecimentos sobre o assunto abordado e verificar outros de interesse do grupo para serem discutidos na próxima oficina de teorização com o Método Problematizador.

Nesta oficina foram feitas diversas perguntas pelo grupo de mulheres gestantes, principalmente em relação aos partos com fórceps e as cesarianas. Trocaram-se idéias, informações e preocupações. Percebemos que as gestantes estavam mais participativas, apresentavam suas dúvidas e questionavam sobre o assunto. Uma das mulheres gestantes fez um desabafo falando da sua dificuldade em aceitar a gestação. Isto mobilizou o grupo a se solidarizar com ela usando palavras de apoio, tentando incentivá-la sobre a continuidade da gestação. Este foi um momento importante da fase de construção do grupo, mostrando a preocupação de uma com a outra.

Encerrou-se a oficina com um cofee-break, descontraindo o grupo e reafirmando o compromisso com o próximo encontro. Nesse momento elas riram, comentaram sobre variados assuntos do cotidiano, falaram sobre o parto de suas tias, mães, avós, vizinhas, conhecendo-se melhor nesta interação. O grupo avaliou o trabalho através do mesmo instrumento utilizado na oficina anterior: quatro mulheres gestantes relataram estar satisfeitas e desejosas de mais encontros.

\section{$4^{a}$ Oficina: estendendo a discussão sobre parto}

$\mathrm{Na}$ quarta oficina compareceram sete gestantes. O encontro começou com uma dinâmica de grupo chamada Caixinha de Surpresa Agradável, a qual auxiliou para que as mulheres demonstrassem confiantes e comunicativas compartilhando idéias. Após esta atividade integradora foram expostos os objetivos do trabalho e iniciada outra etapa de
Teorização, através de cartazes ilustrativos e informativos sobre o parto normal, o parto cesárea, o parto fórceps e a episiotomia.

Realizou-se revisão do encontro anterior, ajudando-se esclarecer algumas dúvidas. Após isso, foram colocados os cartazes no chão e pedido para que uma das participantes pegasse o cartaz que lhe chamava a atenção e que comunicasse o que sabia sobre o mesmo para as demais do grupo. O grupo foi mobilizado da mesma forma com os demais cartazes expostos. Todas participaram ativamente, havendo reflexões e comunicações quanto às mudanças de comportamento no que se referia ao medo em relação ao parto normal. Parecendo mais seguras e confiantes as participantes reconheceram que a opção pelo parto normal é o melhor caminho. Após esse momento, o grupo discutiu sobre a questão dos direitos das gestantes, assunto que seria abordado e aprofundado em outra oficina.

Verificou-se nesta oficina o quanto é importante o conhecimento quando usado como estratégia de transformação do ser. Por outro lado, percebemos que uma das funções do facilitador é criar um clima interativo e mobilizador do grupo à busca do conhecimento. Finalizando, realizou-se o cofee-break, conversou-se sobre vários assuntos, marcou-se o próximo encontro. Demonstrando que estavam felizes, as participantes saíram se despedindo com abraços e beijos. Feita a avaliação da oficina verificou-se que seis mulheres gestantes manifestaram satisfação e desejam que houvesse outras oficinas.

\section{$5{ }^{a}$ Oficina: desmistificando a dor e medo do parto}

Nesta oficina de Teorização contou-se com o apoio de uma psicóloga e uma fisioterapeuta para discutirem com o grupo sobre o medo e a dor do parto. Estavam presentes seis mulheres gestantes. Feita a apresentação das facilitadoras ao grupo, trocaram-se idéias sobre o encontro. A fisioterapeuta propôs conduzir uma conversa informal na qual as profissionais fossem esclarecendo dúvidas levantadas pelo grupo, problematizando situações trazidas pelo mesmo.

A fisioterapeuta orientou a todas sobre a necessidade de se sentirem confiantes e preparadas para o parto, pois, esses aspectos influenciariam no trabalho de parto; ensinou exercícios para serem feitos antes e durante o trabalho de parto explicando que todo o processo é natural e quanto mais a gestante estiver ciente da importância do seu desempenho nesse momento, tudo tende a fluir de maneira mais 
tranqüila. Foi deixado ao grupo um folder com exercícios propostos e um folheto com instruções a serem seguidas.

No intervalo do cofee-break o grupo começou a conversar com a psicóloga sobre a gravidez não desejada e uma das gestantes falou da dificuldade do marido aceitar sua gestação. Retornando à atividade grupal, outras desabafaram falando do medo em morrer durante o parto, do medo do serviço prestado pelo hospital. Buscou-se desmistificar vários tabus na discussão e oportunizou-se o levantamento de sugestões pelo grupo para superar suas dificuldades. A oficina foi mobilizadora e ao seu término o clima era de alegria e satisfação.

\section{$6^{a}$ Oficina: conhecendo um pouco mais sobre os direitos da mulher gestante}

Nesta oficina de Teorização compareceram seis mulheres gestantes. $\mathrm{O}$ assunto à Teorização esteve relacionando às Leis e Programas do Governo para Promoção da Humanização no pré-natal, parto e pósparto, tema surgido na oficina anterior.

Apresentados os cartazes nos quais se lia: Licença Maternidade, Mãe Curitibana, Programa de Humanização no Pré-natal e Nascimento, Lei do acompanhante no parto, foi feito o convite a cada mulher gestante para escolher um deles.

A discussão sobre cada cartaz foi orientada por perguntas, como: O que é o Programa Mãe Curitibana? Quais os seus princípios? Vocês acham que é uma instituição ou um programa? O que é a licença maternidade? Quanto tempo a mãe pode ficar em casa? Existe estabilidade de emprego quando a gestante volta ao trabalho? Além do direito dos cento e vinte dias existe mais algum direito da mãe? A lei do acompanhante no parto existe? Quando ela foi criada? E por que vocês acham que ela foi criada? $\mathrm{O}$ que a Organização Mundial de Saúde espera no atendimento Hospitalar? Qual a preocupação do Ministério da Saúde em Humanizar o Parto? O que é Programa de Humanização no Pré-natal e Nascimento? Quando ele foi criado? Qual o motivo da criação desse programa? De quem é a responsabilidade da implantação desse Programa? Lançada cada pergunta, estimulava-se o grupo à discussão. Houve dificuldades de participação porque o tema sobre direitos não era de conhecimento do grupo.

A facilitadora citou exemplos ou casos para que o grupo refletisse sobre este assunto. Mesmo questionando e incentivando a discussão percebeu-se que o grupo apresentou dificuldades devido à falta de aproximação com os temas. Foram apresentadas pela facilitadora, muitas informações novas para que o grupo fizesse uma primeira aproximação com o assunto. Entregou-se às mulheres gestantes cartilha sobre os Direitos das Gestantes, além de outros materiais educativos. Após o término realizamos o cofee-break, com conversa e descontração. Na avaliação feita todas externaram que se sentiam satisfeitas.

\section{$7^{\circ}$ Oficina: o caminho do grupo na etapa de levantar hipóteses de solução para aplicar à realidade}

Compareceram a esta oficina seis mulheres gestantes. O início da oficina se deu através de uma dinâmica de grupo intitulada Diploma Afetivo, que foi um momento especial, no qual expressaram os sentimentos relacionados aos encontros desenvolvidos. Foram trazidos sete problemas levantados pelo grupo e, aplicando a técnica da tempestade cerebral, as mulheres gestantes foram estimuladas a levantarem soluções para os mesmos.

Após citar possíveis soluções para resolução dos problemas levantados, verificou-se que muitos deles não dependiam da própria mulher gestante para serem resolvidos e sim de instâncias envolvendo o serviço de saúde e seus órgãos responsáveis. Desse encontro saiu a idéia de um documento escrito sobre o que todas gostariam que mudasse em relação ao tratamento recebido na Unidade de Saúde e no Hospital, para ser entregue por elas em dia agendado com os responsáveis tanto da Unidade de Saúde quanto do Hospital.

Observou-se o quanto o grupo evoluiu na análise de sua realidade e na resolução de problemas levantados nas oficinas anteriores. Ficou acordado que a reunião seria marcada e juntas entregaríamos o documento aos serviços de saúde procedendo às explicações necessárias. Assim, estaríamos aplicando à realidade esta ação planejada pelo grupo e finalizando o processo grupal deste estudo.

\section{ANÁLISE DAS INFORMAÇÕES}

As práticas educativas, por meio do Método Problematizador, com o grupo de mulheres gestantes no preparo ao parto, foram uma forma de cuidar que visou oferecer-lhes um suporte social, informativo e de apoio para diminuir o estresse e o medo quanto ao 
parto, preparando-as para enfrentamentos e superações no processo do parto e na hospitalização.

O Método Problematizador tem sido apontado como uma metodologia ativa de ensino aprendizagem que contribui ao desenvolvimento crítico reflexivo dos sujeitos, partindo de uma prática ou de uma situação vivenciada pelos mesmos. Ele proporciona reflexão sobre causas, conseqüências, significados e também reflexão do próprio sujeito, questionando seus papéis, desempenhos e concepções. Neste método todo o trabalho reflexivo tem intenção de transformação, espera-se que os sujeitos ao se depararem com situações problemas em diferentes cenários possam mobilizar atributos construídos para enfrentá-las, intervir e se superarem ${ }^{(7)}$.

Considerando que este estudo teve por questão norteadora o pressuposto de que o Método Problematizador é um método ativo, reflexivo e transformador passamos a descrever como foi feita esta apreensão no processo educativo realizado, na intenção de preparar ao parto um grupo de sete mulheres gestantes.

\section{A realidade do parto na auto-expressão das gestantes}

Nas etapas de Observação da Realidade do Parto e Levantamento de seus Pontos-Chave podese perceber que as gestantes gostam de contar suas experiências vividas na condição de gestantes ou de parturientes. Ao interagirem no grupo, discutindo sobre o parto, comunicaram percepções, idéias e sentimentos que reuniam sobre o parto, permitindo ao facilitador identificar em suas falas, preocupações, expectativas, dificuldades, potencialidades e necessidades de conhecimentos, habilidades para lidar consigo mesma, com o parto, a hospitalização e a assistência de saúde recebida. Algumas falas das participantes do estudo confirmam esta apreensão, localizada nas etapas iniciais de aplicação do Método Problematizador:

Querem aumentar o índice de parto normal, pois no país existe muita cesárea, mas qual o limite para se ter um filho de parto normal? Eles têm que atentar para a criança não ter seqüelas do parto (G2).

Tenho medo do fórceps e não da dor do parto. Ele pode quebrar a clavícula ou machucar a cabeça do bebê. Penso que se o parto for normal pode haver problemas, então eu prefiro a cesárea (G5).
O parto pode ter problemas, pode acontecer por negligência médica. Penso que o médico do programa de saúde da família deveria ter uma especialização para atender a gestante (G7).

Nesta primeira etapa do Método Problematizador, as mulheres gestantes participaram de forma ativa. Todas expressaram suas idéias e sentimentos em relação ao parto, relataram suas experiências pessoais ou aquelas que escutaram de outras gestantes do seu ciclo de amizade, fizeram perguntas ao grupo ou ao facilitador. Foi possível apreender que o método tem um caráter ativo, interativo, proporciona a troca de conhecimentos entre os sujeitos que mostram os conhecimentos que portam da sua experiência com o mundo real.

Percebeu-se em algumas falas no grupo a reflexão da vivência prática com a assistência ao parto. As participantes das oficinas explicitaram a assistência que queriam e a que não queriam no parto, justificando o porquê, argumentando e muitas vezes até propondo hipóteses de soluções aos problemas relatados. Questionadas sobre os fatores e determinantes das situações-problemas ocorridas no processo de parto, as mulheres gestantes conseguiram apontar causas ligadas à qualidade do atendimento.

Nesta etapa não foi possível perceber o caráter transformador do método, porque este é resultado evolutivo da capacidade do grupo em entender, analisar, comparar elementos dentro de situações que problematizam o sujeito, que desequilibram suas crenças ou que agregam novos elementos ao seu conhecimento mudando neles a forma de pensar e falar sobre uma realidade.

Outro momento de exercício reflexivo do grupo ocorreu quando alguns Pontos-Chave sobre a realidade do parto foram levantados e o grupo precisou escolher algumas temáticas para aprofundamento de seus conhecimentos. A escolha recaiu sobre: sinais de parto, tipos de parto, medos e dor do parto, humanização do parto e direitos das mulheres gestantes.

Nestas etapas iniciais de aplicação do Método Problematizador percebemos que o papel do enfermeiro, como facilitador de grupo, deve ser de questionar, incentivar, provocar, ouvir mais do que fornecer informações, porque o centro do processo de ensino-aprendizagem deve ser o grupo. Entendendo que este é portador de conhecimentos, tem percepções sobre a sua realidade e merece ser valorizado quanto aos seus saberes. 


\section{A realidade do parto por outros olhares e conhecimentos}

O ponto de partida da etapa de Teorização do Método Problematizador foram os Pontos-Chave sobre o Parto, escolhidos pelas mulheres gestantes para conhecer mais sobre o tema. Destaca-se que o processo do conhecimento exige um movimento de ida e volta de aproximações sucessivas que vão tornando o mesmo mais profundo e abrangente ${ }^{(8)}$. A cada aproximação do tema Parto, o grupo de mulheres gestantes captava mais elementos e fazia novas associações, reconstruindo seus conhecimentos anteriores.

Foi justamente nas quatro oficinas da etapa de Teorização do Método Problematizador que o grupo construiu respostas às suas perguntas, dúvidas e problemas sobre o Parto, pela aquisição de mais conhecimentos. Percebeu-se, então, que a forma, a extensão e a profundidade da Teorização depende do interesse que do grupo pelo tema bem como sua disponibilidade mental e emocional ${ }^{(5)}$.

Para as oficinas de Teorização foram utilizadas diferentes técnicas de ensino aprendizagem buscando promover a participação das gestantes, contrariando, muitas vezes, a expectativa do grupo que era a do facilitador passar informações como conhecedor do assunto, marca comum do ensino transmissor. Essa etapa exigiu certo esforço mental das gestantes, porque para teorizar é preciso pensar, refletir e isso pode ser difícil quando não se possui o hábito de fazê-lo.

Para discutir as questões sobre o Parto o grupo de mulheres gestantes analisou as questões levantadas para elaborar explicações, apontar hipóteses, perguntar, comparar, julgar, procedimentos estes que reafirmaram outra vez o caráter ativo e reflexivo do Método Problematizador. O exercício de refletir sobre o tema Parto foi desafiante e indispensável para que as mulheres gestantes pudessem olhar ou julgar melhor seus modos de pensar, de escolher, de reconhecer e até de estabelecer ações para agir.

Esta etapa tem como enfoque o fato de os sujeitos exercitarem várias operações analíticas da inteligência, ela é altamente enriquecedora e permite o crescimento mental atingindo um poder de generalização e extrapolação considerável ${ }^{(9)}$.

Considerando que a aprendizagem pelo Método Problematizador resulta da ação do sujeito sobre determinado objeto, este estudo selecionou o preparo para o parto para reflexão de mulheres gestantes. Elas se pronunciaram conforme discursos extraídos de quatro oficinas de Teorização:

E se a bolsa não estourar e eu tiver dores muito fortes, tenho que vir para o hospital ou não (G2)?

Escuto história da minha sogra, que minha cunhada tinha abaixado a barriga. Foi ao médico, estava de $3 \mathrm{~cm}$, teve contração, depois saiu, fez compras e daí que nasceu o bebê. Se não tiver contração, o bebê nasce (G3)?

Acho que é necessária a contração para o bebê nascer, ninguém nasce sem que a mãe sinta dor (G7).

Na primeira oficina de Teorização sobre os Sinais de Parto, algumas mulheres gestantes já mostravam motivação para conhecerem mais sobre os tipos de parto:

Se eu fiz cesárea, posso ter agora um filho de parto normal (G1)?

Quando a mãe não tem dilatação, para ter um parto normal, tem que fazer o parto cesárea (G2)?

Ressalta-se que na Teorização, não é só o facilitador quem problematiza o objeto de reflexão do grupo, mas os próprios participantes do grupo de reflexão. A dinâmica reflexiva tem um movimento interativo, contagiante que põe o grupo em atividade de respostas e perguntas concomitantemente, como se observou na segunda oficina de Teorização com a temática Tipos de Parto.

Nesta oficina, as mulheres gestantes desdobraram reflexões exaustivas sobre o parto fórceps, num processo dialógico e de participação ativa, trazendo dúvidas, mitos, crenças, medos sobre o mesmo:

Eu imagino que o parto a fórceps vai machucar o bebê, sei lá, a gente ouve muito falar que machuca a cabeça do bebê, arranca o bracinho, então, a gente fica desesperada (G5).

Acho que este parto fórceps é judiado, mas é necessário. E, é sofrido para o bebê não sei se para mãe é ou não eu nunca vi, mas imagino que seja algo que encaixe na cabeça e puxe para fora, ajudando o bebê a nascer (G3).

Como ela explicou o neném tem que nascer de 
cabeça para baixo, o meu filho teve que ser rodado, o médico fez com a mão e ele nasceu com uma manchinha roxa na testa (G7).

Concentrando a necessidade de discussão sobre o parto a fórceps, o grupo chegou a comentar as indicações deste procedimento obstétrico e algumas citaram complicações como infecções associadas à técnica de pressão do fórceps na criança e na mãe:

O fórceps é usado quando o bebê está em sofrimento (G6).

Outras idéias agregaram-se ao comentário.

Ou quando o neném não está vindo, ou a cabeça é muito grande (G3).

Ou pode ferir dentro da mãe e também infeccionar os pontos (G5).

Estas e outras lógicas reflexivas do grupo nesta etapa de Teorização sobre os tipos de parto mostraram necessidades de informações a serem fornecidas pelo facilitador do processo educativo, na busca de esclarecer dúvidas, clarear idéias equivocadas e formar novos conceitos.

À observação do movimento reflexivo grupal constatou-se que as mulheres gestantes, como sujeitos de relação com o mundo, são seres que produzem idéias neste caso sobre os partos normal e cesárea, como comprovam as falas nesta mesma oficina de Teorização sobre os tipos de parto:

Já está decidido que o meu parto vai ser parto normal. Converso até com o bebê para que ele entenda a minha vontade, e que é o melhor para nós dois (G3).

Por que quando se faz cesárea fica vinte quatro horas sem levantar (G4)?

Eu vejo mulheres que fazem partos cesárea ficarem com aquela barriga grande, maior do que a pessoa que tem parto normal. Por quê (G5)?

Na oficina de Teorização sobre Medos do Parto, tema apontado na etapa de Levantamento dos PontosChave do Método Problematizador, o grupo de mulheres gestantes foi iniciado à mobilização reflexiva por meio da pergunta feita pelos apoios técnicos que foram convidados à participação, uma fisioterapeuta e uma psicóloga: Que medos vocês tem quanto ao parto?

O caráter aberto da pergunta endereçada ao grupo facilitou a entrada das mulheres gestantes no processo reflexivo de análise e discussão do assunto de maneira ativa, transitando as percepções postas, entre o individual e o coletivo, com diferentes ordens de conhecimentos segundo as falas, aqui transcritas:

Dizem que aqui no hospital onde teremos nosso parto, morreu uma mãe; estamos com medo dessa realidade, fica difícil ter segurança (G4).

Mas, gente, em todo lugar se morre, não é porque é aqui. Outras maternidades também têm óbitos. $O$ fato que nos choca é por ser tratar do hospital da nossa área (G3).

Meu maior problema nesta gravidez é em relação ao meu casamento. Estou com problemas lá em casa, meu marido não queria que eu engravidasse e agora brigamos muito (G6).

O grupo tem sido bom para mim, eu estava bem deprimida por seu uma mãe idosa, e me sentia envergonhada de ter ficado grávida, mas aqui me sinto bem, desabafo e todos me entendem (G7).

O medo neste grupo de mulheres gestantes parece estar relacionado ao que lhe é desconhecido ou ao que vem como apropriação externa pelas suas relações com o ambiente. O medo estava na morte durante o parto, na ausência de garantia da qualidade da assistência, na ruptura dos vínculos familiares, nos preconceitos sociais sobre a idade para se engravidar.

Nesta oficina, o aspecto do clima interativo do grupo aparentou união solidária entre as mulheres gestantes. Houve apoio de umas com as outras, independente da idade gestacional ou mesmo cronológica, independente de suas crenças, de suas situações de vínculos familiares e sociais. Apreendeuse neste encontro que o grupo estava mudado quanto ao comportamento grupal em relação aos encontros iniciais. A vivência interativa e reflexiva estava transformando as mulheres gestantes tornando-as mais colaborativas no apoio mútuo, pacientes com o ritmo de reelaboração mental das colegas, atenciosas umas com as outras. O grupo estava com sua socialização melhor desenvolvida. 
O Método Problematizador permite interação entre as pessoas e relação com o mundo que as cerca, buscando a transformação do sujeito a qual ocorre não só no educador, mas principalmente no educando, sendo assim uma prática social ${ }^{(3)}$. Nesta sintonia, cabe ao enfermeiro no processo educativo desenvolver no grupo aspectos que valorizem e tragam aproximação entre os indivíduos, favorecendo o fortalecimento das potencialidades individuais e grupais, priorizando a valorização da saúde ${ }^{(10)}$.

Na oficina de Teorização sobre Humanização do Parto e Direitos das Gestantes, nossa expectativa estava em articular aos saberes das mulheres gestantes a questão da cidadania, pois a educação tem sido um ato de refletir a evidência de cuidados, ao mesmo tempo em que propõe a humanização das relações e a libertação dos seres humanos para se superarem em situações de vida e saúde ${ }^{(1)}$.

A atividade reflexiva do grupo nesta oficina se mobilizou à medida que o facilitador ao trazer conteúdos relacionados ao Sistema Único de Saúde, Licença Maternidade, Programa Mãe Curitibana e Lei do Acompanhante, provocava-lhe a reflexão. No diálogo estabelecido pelo grupo pode-se perceber que as mulheres gestantes se posicionavam como sujeitos de conhecimento, ora interrogando umas às outras, ora problematizando, ora expressando suas percepções com firmeza, ora fazendo suas críticas e julgamentos.

O clima de aprendizagem foi motivador e o conhecimento ora se fazia, ora se refazia num movimento reflexivo e ativo das gestantes e do facilitador buscando ver com outros olhares o mundo das relações sociais relacionado com a questão da cidadania. Algumas falas apresentadas tornam perceptível o caráter ativo, reflexivo da discussão do grupo.

Sobre o Sistema Único de Saúde, após explicações dadas pelo facilitador, uma das mulheres gestantes, colocou:

Criaram o Sistema Único de Saúde para se levar a saúde a quem não tem acesso atendendo a todos que não tem plano de saúde.(G1)

Acerca da licença maternidade, assunto que pareceu ser de interesse no grupo, a preocupação maior foi relativa ao tempo de gozo da mesma e à condição desse direito:

Mas, só a gestante que trabalha é que tem esse direito? As outras teriam que recolher o INSS (G6)?
É, estão tentando liberar para seis meses; seria melhor para a mãe e bebê, pois poderia assim, realmente amamentar exclusivamente o bebê (G1).

Em se tratando do Programa Mãe Curitibana, houve dúvidas no grupo entre os termos programa e unidade, tornando-se necessário a atuação do facilitador para esclarecer e realinhar a compreensão e a diferença deles.

Eu já ouvi falar que fazemos um acompanhamento no hospital e depois ele encaminha para o posto de saúde para que acompanhe o bebê (G3).

Mãe Curitibana é um programa direcionado para mães? Eu ouvi falar dele, mas não sei como funciona. Tem uma unidade da Mãe Curitibana, lá na cidade, já fiz um exame, lá! (G7).

O processo do Método Problematizador leva os sujeitos a se instruírem e a conscientizarem-se de seu papel, de seus deveres e direitos na sociedade ${ }^{(5)}$.

Motivadas por essa percepção da realidade de seus direitos, as mulheres gestantes prosseguiram dialogando e interagindo nesta oficina de Teorização, expressando suas idéias sobre a Lei do Acompanhante, assim como seus pontos de vista sobre algumas contradições na aplicação da lei pelos serviços de saúde:

Mas se existe essa lei, por que temos que fazer o curso de acompanhante do hospital? Se eu não puder fazer, vou exigir que meu acompanhante entre no parto (G4).

Essa lei nem sempre é cumprida. Temos que exigir nosso direito (G7).

Mas se você está morrendo de dor, vai ter condições de brigar por essa lei? E se eles não quiserem me atender? E se me mandarem para casa, como vou fazer (G6)?

O Centro Médico desse estudo oferece às mulheres gestantes curso de acompanhante. Alguns comentários mostram o que as participantes pensam a respeito:

O curso esclarece o acompanhante, evitando que o mesmo se sinta apavorado, deixando a mãe nervosa também (G1). 
Acho importante fazer o curso de acompanhante, pois trazem esclarecimentos sobre como é o parto e o risco de passar mal na hora fica menor (G7).

O curso deveria mostrar vídeos de uma mulher ganhando bebê (G3).

O papel do facilitador na Teorização é captar o nível de conhecimentos do grupo e ajudá-lo a entender por outros conhecimentos, o porquê de determinados problemas, suas manifestações e suas determinações ${ }^{(9)}$. Logo, a Teorização por proporcionar a atividade reflexiva do grupo aumenta as possibilidades de crescimento mental e as habilidades para aplicar os conhecimentos elaborados à vida real. Quando isto acontece com o indivíduo ou com o grupo o caráter transformador do método se torna perceptível.

\section{As hipóteses de solução na pauta do trabalho grupal}

Esta fase consiste de o facilitador apresentar ao grupo os problemas por ele levantados para a elaboração de possíveis hipóteses de solução(11).

No processo de aplicação do Método Problematizador com o grupo de mulheres gestantes participantes deste estudo, os problemas levantados diziam respeito às relações estabelecidas com os profissionais e os serviços de assistência à saúde da mulher gestante.

Apresentados os problemas pelo grupo em oficinas anteriores, o facilitador incentivou o grupo a formular Hipóteses de Solução procedendo ao registro das mesmas e posteriormente à seleção daquelas mais viáveis e factíveis dado as limitações da realidade. As atividades de análise, julgamento, argumentação, troca de conhecimentos, indicações das hipóteses de solução aos problemas apresentados permitiram apreender o caráter ativo e reflexivo do Método Problematizador.

O grupo apontou algumas solicitações que gostaria de apresentar ao centro de especialidades e ao centro médico de seu bairro, firmando este posicionamento conforme as falas abaixo transcritas:

Podemos entregar as nossas solicitações na unidade e no hospital. Vamos todas juntas (G3).

Não vejo problemas, afinal é nosso direito. Se não nos colocarmos, como os serviços saberão se as coisas estão certas ou erradas (G2)?

Percebe-se o quanto o grupo amadureceu pela reflexão, para começar a agir. Ao usar a realidade o grupo aprendeu com ela, ao mesmo tempo iniciou o preparo para transformá-la pela ação, ou seja, a tomada de posição para intervir na realidade. Esta foi uma oportunidade reveladora do caráter transformador do Método Problematizador.

\section{Agindo na realidade}

A Aplicação à Realidade da etapa do Método Problematizador leva o grupo a tomada de decisões à prática na realidade. Espera-se com isso que o grupo esteja desenvolvido para intervir e transformar ${ }^{(9)}$.

Durante o último encontro do grupo foi definido que o mesmo entregaria aos serviços de saúde um documento contendo sugestões de mudanças no atendimento ao grupo e a outras mulheres gestantes que precisassem desses serviços. Este documento foi elaborado e entregue através de uma representante do grupo de mulheres gestantes, para a responsável pela Unidade de Saúde e do centro Médico. Nesta ocasião foram lidas e entregues as sugestões que o grupo tinha como contribuições para mudar a realidade do atendimento de saúde no local.

Observa-se que houve receptividade por parte das enfermeiras ao documento, havendo atitude atenciosa com a representante do grupo que falou das sugestões encaminhadas pelo grupo. As enfermeiras representantes do serviço explicaram que as solicitações seriam repassadas para toda a equipe.

Após apresentar esta pauta de solicitações aos serviços de saúde como contribuição participativa à melhoria da qualidade do atendimento, consideramos que as mulheres gestantes deste estudo desenvolveram alguns atributos que lhes possibilitaram uma intervenção transformadora.

\section{CONSIDERAÇÕES FINAIS}

Analisar a aplicação do Método Problematizador no cuidado educativo de um grupo de mulheres gestantes foi uma experiência instigante, porque trouxe o desafio de aplicar esse método educativo e observar seu caráter ativo, reflexivo e transformador a nível individual e coletivo.

O Método Problematizador é mais uma possibilidade para sensibilizar as pessoas sobre 
comportamentos em saúde e nas suas relações com os serviços de saúde. No entanto, percebe-se que na aplicação do Método o facilitador precisa saber questionar o grupo, incentivar, problematizar as idéias postas pelos educandos para desafiá-los a refletir. Cabe a ele colocar o pensamento do grupo em movimento, porque neste método o centro da aprendizagem é o educando.

Foi possível também notar que o método tem um caráter transformador. Essa transformação nos educandos pode ser apreendida quando os mesmos assumem posicionamentos que não tinham antes, quando reelaboram seus conhecimentos usando formas diferentes de falar, quando mostram atitudes de apoio e afeto uns com os outros. Pode-se verificar que valores como respeito confiança, solidariedade, responsabilidade, são expressões de transformação que podem aparecer no trabalho educativo pelo Método Problematizador.

Como conquista e reconhecimento do resultado deste estudo será dado continuidade ao mesmo produzindo um Guia prático para a realização de atividades educativas com gestantes e puérperas, material que será utilizado no Distrito Sanitário para instrumentalizar e orientar os profissionais da saúde, em suas ações educativas.

\section{REFERÊNCIAS}

1. Miranda LCK, Barroso TGM. A contribuição de Paulo Freire à prática e educação crítica em enfermagem. Rev Latino-Am Enferm. 2004;12(4):631-5.

2. Freire P. Pedagogia da autonomia: saberes necessários à prática educativa. 12ª ed. São Paulo: Paz e Terra; 1999.

3. Girondi JBR, Nothaft SCS,Mallmann FMB A Metodologia problematizadora utilizada pelo enfermeiro na educação sexual de adolescentes. Cogitare Enferm. 2006;11(2):161-5.

4. Bordenave JD, Pereira AM. Estratégias de ensinoaprendizagem. Rio de Janeiro: Vozes; 2004.

5. Berbel NAN. Metodologia da problematização: experiências com questões de ensino superior. Londrina: UEL; 1998.

6. Martins SK, Kalinowski CE. Revendo o enfoque educativo no processo de amamentação. Cogitare Enferm. 2001 Jul/Dez;6(2):59-63.

7. Laluna MC, Rosa RSL, Pereira SMSF. Metodologias inovadoras de ensino aprendizagem. Olho Mágico 2005;12(4):101-7.

8. Vasconcelos CS. Metodologia dialética em sala de aula. Rev Educ Rio Grande do Sul. 1992;83:28-52.

9. Bordenave JD. Alguns fatores pedagógicos. In: Brasil. Capacitação pedagógica para instrutores/supervisores da área de saúde. Brasília: Ministério da Saúde;1990. p. 19-26.

10. Alonso ILK. O processo educativo em saúde na dimensão grupal. Texto Contexto Enferm. 1999;8(1):12232.

11. Berbel NA. A problematização e a aprendizagem baseada em problemas: diferentes termos ou diferentes caminhos. Interface Comunicação, Saúde, Educação. 1998;2(2):139-54. 